\title{
Intravenous Iron Sucrose Therapy in Anemia with Pregnancy
}

\author{
Dr.Mahassin Qassim Qaddori \\ MB.chB ,Diploma in gynecology\&obstetrics Baghdad university college of medicin
}

\begin{abstract}
Anemia of pregnancy is most common medical disorder in the developing country, affecting 2 billion population worldwide. In India prevalence is $49.7 \%$ of pregnancy contributing to $80 \%$ of maternal mortality. Parental iron therapy produces rapid, complete correction of iron deficiency including iron stores. Intravenous iron sucrose therapy has become gold standard in management. It has many advantages over other iron preparations in correction of anemia.AIMS AND OBJECTIVE: Evaluation of hemoglobin improvement, time required, and patient's compliance after iron sucrose therapy.MATERIAL AND METHODS: Retrospective analysis was done of 264 pregnant women with anemia who were admitted in AL-Zahra Teaching Hospital from May 2015 to August 2019, and were diagnosed as iron deficiency anemia and had received intravenous iron sucrose $200 \mathrm{mg}$ weekly till targeted hemoglobin 10gm was reached.RESULTS: majority of women $(54.2 \%)$ were in age group of $21-29$ years. $66.3 \%$ were resident of rural area. Anemia was more common $(69.7 \%)$ in women with vegetarian diet. $83 \%$ of patients were multigravida. $48.9 \%$ cases were of mild, $44.7 \%$ of moderate, and $6.4 \%$ of severe anemia. There was initial rise in $\mathrm{Hb}$ within a week and rise of $1-2 \mathrm{gm} \mathrm{Hb}$ per week attaining a targeted $\mathrm{Hb}$. CONCLUSION: Iron sucrose is the best tolerated drug, gives mean $\mathrm{Hb}$ rise by $600 \mathrm{mg}$ in all grades of anemia and in maximum periods of 4 weeks. Looking at the patient's compliance and feasibility this drug has replaced strategy of unnecessary blood transfusions.
\end{abstract}

Keywords: Anemia of pregnancy, Pareneteral therapy, Iron sucrose therapy.

DOI: $10.7176 / \mathrm{JHMN} / 81-07$

Publication date:October $31^{\text {st }} 2020$

\section{INTRODUCTION}

Anemia in pregnancy affects 2 billion population in the world. Most common in Asia and Africa. 1 In India more than $50 \%$ pregnant women suffer from anemia contributing to most common cause of maternal mortality and morbidity. $76 \%$ of all anemia were found to be microcytic and hypochromic. 2,3 Iron deficiency anemia is due to low iron stores in body. It begins in childhood, worsens during adolescence and gets aggravated during pregnancy. Data from the NNMB4 showedthat iron and folic acid intake was very low in all age group in the country. Poor iron stores at birth4 low iron content in breast milk, low dietary intake of iron in infancy and childhood, gets worsened in adolescent. Multi parity, abortions, Menorrhagia, malaria and hookworm, tuberculosis, urinary tract infection, malabsorption, food cooking habits, high phytate diet5 all contribute to iron deficiency in India. 6,7 Pregnant women enrolled at 20-26 weeks of pregnancy showed that, $75 \%$ had mild anemia, $14.8 \%$ had moderate and $0.7 \%$ had severe anemia (Hemoglobin $(\mathrm{Hb})$ below $7 \mathrm{gm} / \mathrm{dl}$.). Major effect of anemia in pregnancy is maternal and neonatal mortality and morbidity8,9 Anemia causes preterm birth, pregnancy induced hypertension, eclampsia, placental abruption, hypotonic uterine contraction, atonic postpartum hemorrhage, puerperal sepsis. fetal risk includes, intrauterine growth retardation, prematurity, poor apgar score, fetal distress, neonatal anemia. Infants have failure to thrive, poorer intellectual developmental milestones 10. This highlights the importance of diagnosis and treatment of anemia at all age group with special emphasis in pregnancy. Skilled management of severe grades of anemia detected in late pregnancy, by blood transfusions and parental iron therapy became the hallmark of good obstetric practice resulted in maternal and prenatal salvage. 11 Government of India included routine iron and folic acid supplement to children, pregnant and postpartum mothers in maternal and child health program. But due to poor compliance at all level anemia could not be prevented by oral iron therapy indicates the level of ignorance and indifference to health needs. There is an urgent need to educate pregnant women and their families about the importance of antenatal care and optimum family size. Oral iron therapy though is first line treatment but has its own limitations. In women with chronic blood loss, gastrointestinal diseases, poor compliance, oral iron fails to meet the iron demand. These women are benefited by parental iron therapy. 12 This therapy produces rapid and complete correction of iron deficiency producing more rapid erythropiotic response than oral iron therapy. 13 Therefore intravenous iron has become a Holy Grail in the management of iron deficiency anemia (IDA) in pregnancy in our country. Iron sucrose has got more safety, rapid response, as compared to iron dextran, iron sorbital and iron gluconate as well as blood transfusion. 12,14 Unlike other iron preparations, iron sucrose can be given without any test dose with no reported serious adverse reaction. Hence iron sucrose appears to be a treatment of choice for safe and rapid correction of anemia. AIMS AND OBJECTIVE: 1. Evaluation of Hemoglobin improvement after iron sucrose administration. 2. Estimate time required for Hemoglobin improvement. 3. To test patient compliance and feasibility with intravenous iron sucrose. 


\section{MATERIAL AND METHODS}

Retrospective study of 264 pregnant women diagnosed as iron deficiency anemia, admitted in Al-zahra Teaching Hospital for treatment, from May 2015 to August 2019 was undertaken. They were treated with iron sucrose therapy, $200 \mathrm{mg}$ per week till targeted hemoglobin of $10 \mathrm{gm} / \mathrm{dl}$ was reached. Weekly estimate of Hemoglobin $(\mathrm{Hb})$ improvement test was done before each dose of iron sucrose. $200 \mathrm{mg}$ iron sucrose was dissolved in $200 \mathrm{ml}$ normal saline and transfused in 30 minutes. Patients were observed for any transfusion reaction. Results variables include demographic variables, age, parity, diet, gestational age, hemoglobin concentration in inferential statistics. We applied Chi-square test, student paried T test. All statistical analysis were done with the help of SPSS version 20.0 software. Results were tabulated as under.

\section{RESULTS}

Total 264 pregnant women were enrolled in the study

1: Age Distribution of the Patients age 21-29years.no.of cases 143 percentage 54.2 .age 30-39years.no.of cases 94.percentage 35.6 age $>40$ no. of cases 27 percentage 10.2 .

2.Geographical Distribution of Patients Rural no.of cases 175 percentage 66.3 Urban no. of cases 89 percentage 33.7

3: Dietary Pattern of the Patients Veg no.of cases 184 percentage 69.7 Non veg no.of cases 80 percentage 30.3

4: Parity wise Distribution of Anemia Primigravida no.of cases 45 percentage 17 Multigravida no. of cases 219 percentage 83

5: Distribution of Anemic Cases According to Gestational Age 24-28 weeks no. of cases 118 percentage 44.7 8-32 weeks no.of cases 82 percentage 31.1 - >32 weeks no. of cases 64 percentage 24.2

6: Distribution of Cases according to Initial Hemoglobin Leval (Mild, moderate, severe) .sever less than $7 \mathrm{gm}$ no. of cases 17 percentage 6.4 . moderate 7-8 gm no. of cases 118 percentage 44.7 mild 8-9.9 no. of cases 129 percentage 48.9

7: Dose of Iron Sucrose Required In Anemic Women . Dose 200mg no. of cases 53 percentage 20.1 .Dose $400 \mathrm{mg}$ no.of cases 26 percentage 9.8 .Dose $600 \mathrm{mg}$ no.of cases 154 percentage 58.3 . Dose $800 \mathrm{mg}$ no.of cases 31 percentage 11.7

8: Weekly Rise in Mean Haemoglobin after Each 200mg of Iron Sucrose Given in Various Grades of Anemia .Severe anemia no. of cases 17 .Baseline hemoglobin $5.31 \mathrm{gm} / \mathrm{dl} 1$ week Hb (200mg)6.69gm?dl 2week Hb $(200 \mathrm{mg}) 7.54 \mathrm{gm} / \mathrm{dl} 3$ week $(200 \mathrm{mg})) 8.66 \mathrm{gm} / \mathrm{dl} 10.84 \mathrm{gm} / \mathrm{dl} 4 \mathrm{week}(200) 800 \mathrm{mg}$ Moderate anemia no. of cases 118 Baseline hemoglobin 7.26gm/dl 1 week Hb $(200 \mathrm{mg}) 8.57 \mathrm{gm} / \mathrm{dl}$ 2week Hb $(200 \mathrm{mg}) 9.27 \mathrm{gm} / \mathrm{dl} 3$ week (200mg) $10.8 \mathrm{gm} / \mathrm{dl} 4$ week(200) _ Mild anemia no. of cases 14 Baseline hemoglobin $8.35 \mathrm{gm} / \mathrm{dl} 1 \mathrm{week} \mathrm{Hb}$ (200mg) $8.29 \mathrm{gm} / \mathrm{dl} 2$ week Hb (200mg) $8.82 \mathrm{gm} / \mathrm{dl} 3$ week $(200 \mathrm{mg}) \quad 9.50 \mathrm{gm} / \mathrm{dl} 4$ week(200) $10.78 \mathrm{gm} / \mathrm{dl} \mathrm{no}$. of cases 37 Baseline hemoglobin $8.89 \mathrm{gm} / \mathrm{dl} 1$ week Hb (200mg) 9.39gm/dl 2week Hb (200mg) 9.69gm/dl 3 week (200mg) 10.73gm/dl_ no. of cases 24 Baseline hemoglobin $8.75 \mathrm{gm} / \mathrm{dl} 1$ week Hb (200mg) 9.74gm/dl 2 week Hb (200mg) $10.75 \mathrm{gm} / \mathrm{dl} \ldots$ no. of cases 53 Baseline hemoglobin $9.30 \mathrm{gm} / \mathrm{dl} 1$ week Hb (200mg) $10.63 \mathrm{gm} / \mathrm{dl}$

\section{DISCUSSION}

In the present study majority of cases belongs to the age group of 21-29 years, having a mean age of 25.67 \pm 3.7 years which is comparable with study of Prasanna B et al in 2014, Sunita Dubay, Vanita Suri et al, in 2013 observed mean age of $24.23 \pm 3.8$ years and $25.53 \pm 2.93$ years respectively. Agrawal et al in 2012 observed mean age of anemia as $28.1 \pm 5.36$. This indicate that age is not the predominant factor which can determine prevalence of anemia of pregnancy. In the present study majority of women $(66.3 \%)$ belonged to rural area. Divakar et al, in 2012 and Judhith A Naronha in 2008 had observed same result $69.4 \%$ and $70 \%$ respectively, 15 it means rural women are more likely to be affected by anemia of pregnancy. In the present study $69.7 \%$ of the women were vegetarian by diet. Judhith A Naronha15 and Sharma JB, Soni D et al, 16 observed that 50.74\%, and 96.18 women were found vegetarian by diet in their study, this highlights that anemia is more common in women consuming vegetarian only diet. In the present study $83 \%$ anemic women were multigravida, which is slightly higher compared with the study conducted by Agrawal Rohina et al, 17 in 2010, Judhith A Naronh et al in 2008 and Awasthi et al, 18 in 2001. They found that $60 \%, 61.4 \%$, and $65.5 \%$ pregnant anemic women were multigravidas respectively. This proves that anemia is more common in multigravida due to maternal depletion of iron stores caused by repeated pregnancy. $17 \%$ primigravida women were anemic in present study, It may be due to low iron stores in childhood and adolescent age. In the present study all women had anemia after 24 weeks of pregnancy, 24-28 weeks (44.7\%), 28-32 weeks $(31.1 \%)$ and $>32$ weeks $(24.2 \%)$. This denotes that the late second trimester Is very vulnerable for anemia of pregnancy. This result is comparable with study of Prasanna B et al, 19 Sunita Dubey, 20 Alka Kriplani et al, 21 Agrawal R, 17 who detected maximum incidence in $26.3 \pm 4.07$ weeks, 29.68 weeks, 25.69 weeks, $28.2 \pm 2.30$ weeks and 28.2 weeks respectively. Advancing gestational age significantly increases the risk of anemia due to physiological increase of plasma volume and 
more requirement of iron for building up of hemoglobin mass at this gestational period.Signaling meticulous planning for the treatment and prevention of iron deficiency anemia. In the present study $48.9 \%$ women were having mild, $44.7 \%$ moderate and $6.4 \%$ severe anemia. Our study is comparable to the study conducted by Judhith A Noronha et al in 2008 who found $63.5 \%$ were mildly anemic $35 \%$ moderately anemic, $1.5 \%$ severely anemic. Alka Kriplani et al in 2013 found that, 68\% were moderately anemic and 32\% mildly anemic. This indicates that mild and moderate anemia is more common as compared to severe anemia during pregnancy In the present study the minimum iron sucrose required to achieve the target hemoglobin of $10 \mathrm{gm} / \mathrm{dl}$ was $200 \mathrm{mg}$ and maximum iron sucrose was $800 \mathrm{mg}$. In other studies conducted by Bhupesh Dewan et al, 22 in 2012, Christopher et al, 23 in 2011, Christian Breyman et al, 24 in 2006 maximum dose required was 1050mg, 1200mg and 1600 $\mathrm{mg}$ and the minimum dose required was $100 \mathrm{mg}, 300 \mathrm{mg}, 400 \mathrm{mg}$ respectively.During pregnancy approximately $700-1400 \mathrm{mg}$ total iron is required. The fetal iron requirement during pregnancy is $20 \mathrm{mg}$ at 20 weeks, 200mg at 32 weeks, $300 \mathrm{mg}$ at 36 weeks. Hence there becomes a negative iron balance during pregnancy and dietic iron is not enough to meet the daily requirement especially in the second half of the pregnancy.

\section{CONCLUSION}

On the basis of results we conclude that: 1 . Iron deficiency anemia is more common in the age group of 21-29 years, in rural population, consuming vegetarian diet only and in multigravida, after 24 weeks of pregnancy. 2 . Mild and moderate anemia is more common than severe anemia. The best target achievement of $4 \mathrm{gm}$ was attained in 4 weeks and as most of the women reported in late second trimester, they had the ideal benefit of gaining hemoglobin before the delivery. 3. Iron sucrose is the best tolerated drug giving mean hemoglobin rise by $600 \mathrm{mg}$ iron in all grades of anemia and in maximum period of 4 weeks. Hence looking at patient compliance and feasibility this drug has replaced the strategy of unnecessary blood transfusions.

\section{REFERENCES:}

1. De Maeyer, E., Adiels-Tegman, M \& Raystone, E. 1985. The prevelance of anemia in the world.World Health Stat Q., 38: 302-316.(Balaranjan Y, Ramakrishnan U, Ozaltin E, et al. Anemia in low income and middle income countries. Lancet2011; 378: 2123-35.

2. Pena-Rosas JP, Viteri FE. Effects and safety of preventing oral iron or iron and folic acid supplementation for women during pregnancy.Conchrane Database Systematic Review 2009; 4: CD004736.

3. Seshadri S. Prevalence of micronutrient defiency particularly iron, zinc and folate in pregnancy women in South East Asia. BR J Nutr 2001; 85(2): 87-92.

4. Kilbridge J, Bakea TG, Parapia LA, Khoury SA, Shigaidef SW, Jerwood D.Anemia during pregnancy asa risk factor for iron deficiency anemia in infancy: a case control study in Jordan. Int J epidemiol 1999; 28: 461-8.

5. Baig-Ansari N, Badruddin HS, Karmaliani R, Harris H, Jehan I, Pasha O, et al. Anemia prevalnace and risk factors in pregnant women in an urban area of Pakistan 2008; 29(2): 132-39.

6. ACP Hospitalist, March2012 - Parenteral iron for pre- operative iron deficiency anemia: a safe choice?

7. Rock WA Jr. Meeks GR Managing anemia and blood loss in elective gynecologic patients; The Journal of Reproductive Medicine (2001, 46(5suppl): 507-514).

8. Allen LH. Anemia and iron deficiency: Effects on pregnancy outcome. American Journal of Clinical Nutrition2000; 7(5): 1280-84.

9. Steer PJ. Maternal hemoglobin concentration and birth weight. Americal Journal of Clinical Nutrition 2000; 71: 1285-87.

10. Patra S, Pasrija S, Trivedi SS, Puri M. Maternal and perinatal outcome in patients with severe anemia in pregnancy. International Journal of Gynecology and Obstetrics 2005; 91: 164-65.

11. Lawson JB. Anemia in Pregnancy. In: Lawson JB, Stewart DB, editors.Obstetrics and Gynecology in tropics. London: Edwards Arnold; 1967.

12. Scot BS. And George MR. Parenteral iron therapy option. AM J 2004: 76: 74-8

13. UNICEF\UNO \WHO GENEVA 2001. Iron deficiency anemia, assessment, prevention and control.

14. Chandler G, Harrchowal J, Macdougall IC. Intravenous iron sucrose: establishing a safe dose. AM J Kidn Dis 2001; 38: 988-91.

15. Judhith A. Norohna, Aparna Bhaduri and H. Vinod Bhat; prevalence of anemia among pregnant women: a community-based study in udipi district. Health and Population-Perspectives and Issues 31 (1): 31-40, 2008.

16. Sharma JB!, Soni D, Murthy NS, Malhotra M; Effect of dietary habits on prevalence of anemia in pregnant women of delhi. J Ostet Gynaecol Res. 2003 Apr; 29(2): 73-8.

17. Aggarwal Rohina S, Mishra Vineet V, Panchal Navin A, Patel Nital H, Deshchougule Vrushali V, Jasani Anil F. Evaluatio of iron sucrose and oral iron in management of iron deficiency anemia in pregnancy; National Journal of Community Medicine 3(1): Jan-March 2012.

18. Awasthi A, Thakur R, Dave A, et al.Maternal and perinatal outcome in cases of Moderate and Severe 
anemia. J Obstet Gynaec of India.2001 Dec; 51(6): 62-65.

19. Prassana B, Naimisha M, Jhansi Ch B, Mahaboob V Shaik, Safety and Efficacy of High Dose Intravenous Iron Sucrose for Treating Anemia in pregnancy. Sch. J. App.Med.Sci.'2014; 2(2B): 625-627.

20. Sunita Dubey, Vanita Suri, Neelam Aggarwal, Reena Das; is it safe to intravenous iron sucrose during pregnancy? A randomized controlled trial. Int J Reprod Contracept Obstet Gynaecol. 2013 Dec; 2(4): 544549.

21. Alka Kriplani, Reeta Mahey, Biswa Bhushan Dash, Vidhushi Kulshreshta, Nutan Agarwal \& Neerja Bhatla; Intravenous iron sucrose therapy for moderate to severe anemia of pregnancy. Indian JMed res 138, July 2013 78-82.

22. Bhupesh Deewan, Nisha Philipose, and Aarathi Balasubramanian; Assesment of Intravenous Iron Sucrose in the Management of Anemia in Gynaecological and Obstetrical Practise. J Obstet Gynaecol India. June 2012; 62(3): 281-285.

23. Patricia Christophl, Christine Schuller, Hanna Studer, Olivier Irion2, Begofra Martinez De Tejada2 and Daniel Surbekr; Intravenous iron treatment in pregnancy: comparison of high-dose ferric caroxymaltose vs. iron sucrose. Jpm-2011-0231

24. Christian Breymann; The Use of Iron Sucrose Complex for Anemia in Pregnancy and the Postpartum Period. Semin Hematol 43 (suppl 6): S28-S3. 